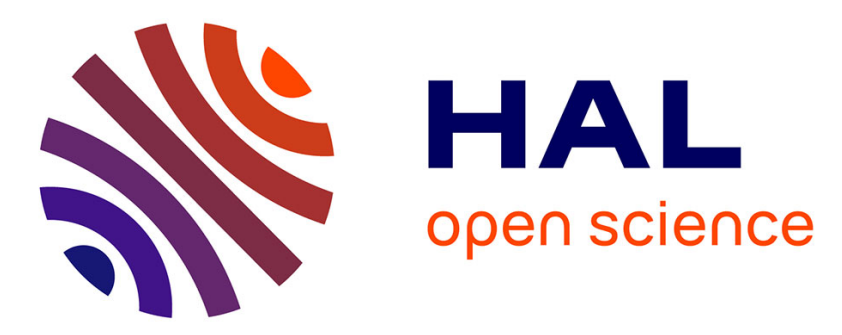

\title{
Influence of indium on the dissociation of dislocations in GaAs at high temperature
}

\author{
M. Jimenez-Melendo, A. Djemel, J.P. Rivière, J. Castaing, C. Thomas, M.
}

Duseaux

\section{- To cite this version:}

M. Jimenez-Melendo, A. Djemel, J.P. Rivière, J. Castaing, C. Thomas, et al.. Influence of indium on the dissociation of dislocations in GaAs at high temperature. Revue de Physique Appliquée, 1988, 23 (3), pp.251-255. 10.1051/rphysap:01988002303025100 . jpa-00245768

\section{HAL Id: jpa-00245768 https://hal.science/jpa-00245768}

Submitted on 1 Jan 1988

HAL is a multi-disciplinary open access archive for the deposit and dissemination of scientific research documents, whether they are published or not. The documents may come from teaching and research institutions in France or abroad, or from public or private research centers.
L'archive ouverte pluridisciplinaire HAL, est destinée au dépôt et à la diffusion de documents scientifiques de niveau recherche, publiés ou non, émanant des établissements d'enseignement et de recherche français ou étrangers, des laboratoires publics ou privés. 


\title{
Influence of indium on the dissociation of dislocations in GaAs at high temperature
}

\author{
M. Jimenez-Melendo $\left({ }^{*}\right)$, A. Djemel, J. P. Rivière, J. Castaing, C. Thomas $\left({ }^{1}\right)$ \\ and M. Duseaux $\left({ }^{1}\right)$ \\ Laboratoire de Physique des Matériaux, CNRS, Bellevue, 92195 Meudon Cedex, France \\ ( ${ }^{1}$ ) Laboratoires d'Electronique et de Physique Appliquée (LEP), B.P. 15, 94451 Limeil-Brevannes Cedex, \\ France
}

(Reçu le 22 octobre 1987, accepté le 11 décembre 1987)

\begin{abstract}
Résumé. - Des dislocations ont été introduites dans GaAs dopé à l'indium par déformation plastique entre $773 \mathrm{~K}$ et $1373 \mathrm{~K}$. Des observations en microscopie électronique en transmission ont montré que l'indium augmente la largeur de dissociation. Cela permet d'expliquer la réduction de densité de dislocations de croissance dans GaAs dopé à l'indium.
\end{abstract}

Abstract. - Dislocations have been introduced in GaAs doped with indium, by plastic deformation between $773 \mathrm{~K}$ and $1373 \mathrm{~K}$. Transmission electron microscope observations have shown that indium increases the width of dissociation. This can explain the reduction of as-grown dislocations in In doped GaAs.

\section{Introduction.}

The use of GaAs for integrated circuits and optoelectronic devices is limited by the occurrence of lattice imperfections. Dislocations, eventually, introduce electronic levels; their stress field modifies the properties of pre-existing defects [1]. Therefore, the aim of crystal growers is to obtain crystals with the greatest perfection. It is now recognized that the addition of the isoelectric dopant indium permits to obtain $\mathrm{GaAs}$ crystals of low dislocation density [2, 3]. The explanation commonly accepted is that In atoms harden $\mathrm{GaAs}$ to a level such that the critical resolved shear stress (CRSS) on the various slip planes is larger than the stresses induced by the growth process. This hardening has recently been shown by performing mechanical tests at temperatures as high as $1373 \mathrm{~K}$ [4-6] $\left(T_{M}=1511 \mathrm{~K}\right.$, melting temperature) corresponding to the assumed ones for dislocation multiplication during growth.

In particular, dislocation-indium interactions give rise to static and dynamic strain ageing [6]. Indium hardening at high temperature is, therefore, well documented. This effect gives one way to understand

(*) Permanent address : Dpto de Optica, Facultad de Fisica 41080 Sevilla, Spain. the improvement of In-doped GaAs crystals due to a decrease of dislocation mobility in their slip plane.

As-grown GaAs single crystals generally display a dislocation cell structure [2], which can be formed only if glide is not restricted to one plane, i.e. crossslip or climb have to be easy. For dissociated dislocations, the possibility of cross-slip events or of climb decreases when the distance between partials increases. This could be the clue to an additional explanation for the beneficial influence of indium on GaAs crystal perfection. Indeed, solute atoms are known to decrease the stacking fault energy in f.c.c. metals, an effect which can be even stronger at high temperature. We have therefore undertaken a detailed study of the influence of indium on the dissociation of dislocations in GaAs submitted to high temperatures.

There has been a number of transmission electron microscopy (TEM) studies on the microstructure of deformed GaAs [7-11] including some atomic resolution observations [12-14]. Only our previous work [11] gave some results on indium doped GaAs, which contained a level of dopants lower than in the present study.

\section{Experimental techniques.}

Semi-insulating GaAs single crystals with 1 to 
$4 \times 10^{20}$ In atoms per $\mathrm{cm}^{3}$ and $10^{16} \mathrm{Cr}$ atoms per $\mathrm{cm}^{3}$ have been grown at LEP, by the liquid encapsulated Czochralski technique. The density of grownin dislocations was about $10^{2} \mathrm{~cm}^{-2}$. Specimens were cut for deformation; the details of the experimental procedure can be found in earlier papers $[4,6,11]$. Dislocations were introduced by compression at a constant strain rate $\dot{\varepsilon}=2 \times 10^{-5} \mathrm{~s}^{-1}$. The stress was applied along the $\langle 001\rangle$ directions, submitting four symmetrical $\langle 1 \overline{1} 0\rangle\{111\}$ slip planes to the same shear stress. Tests were performed in the temperature range between $773 \mathrm{~K}$ and $1373 \mathrm{~K}$, the specimens being immersed in liquid $\mathrm{B}_{2} \mathrm{O}_{3}$ [4]. Deformations were stopped at a strain $\varepsilon=0.03$. A few undoped GaAs single crystals have been studied for the purpose of comparison.

Slices for TEM were cut from deformed samples, at an angle $10^{\circ}$ from a slip plane to identify the direction of the stress $\sigma$ in the foil and to obtain easily the two beam conditions of diffraction when using tilt rotation goniometer.

Thin foils transparent to electrons were obtained by chemical thinning, as described earlier [11]. Observations were made using a JEOL machine operating at $100 \mathrm{kV}$.

Most thin foils contained precipitates, with features definitely different from the dark spots previously observed [11]. The precipitates were square or hexagonal in shape. They were found in doped and undoped specimens deformed at $1173 \mathrm{~K}$ and $1273 \mathrm{~K}$. Their sizes are between $60 \mathrm{~nm}$ and $500 \mathrm{~nm}$ with an average density of $4 \times 10^{4} \mathrm{~cm}^{-2}$ on the TEM micrographs. These precipitates probably originate from impurities which cannot be retained in solution during the annealing and cooling of the mechanical tests. If we take an average precipitate size of $100 \mathrm{~nm}$, a foil thickness of $0.2 \mu \mathrm{m}$ and an atomic density of $5 \times 10^{22} \mathrm{~cm}^{-3}$, one calculates an upper limit for the impurity concentrations of the order of $10^{17} \mathrm{~cm}^{-3}$ (namely a thousandth of the dopant concentration).

The origin of these precipitates has not yet been clearly established. They do not show any relation to dislocation structures and play no role during the plastic deformation.

\section{Results and discussion.}

3.1 Dislocation arRangements. - Figure 1 shows an example of the dislocation structure in an In doped GaAs, deformed at $923 \mathrm{~K}$. Dislocations are along $\langle 110\rangle$ and $\langle 112\rangle$ directions, an observation already made by various authors $[7,15]$ for similar conditions of deformation. The $\langle 110\rangle$ directions are along the intersection of the (111) plane of the foil with the (111) and (1111) planes which are all slip planes. The structure of figure 1 corresponds to

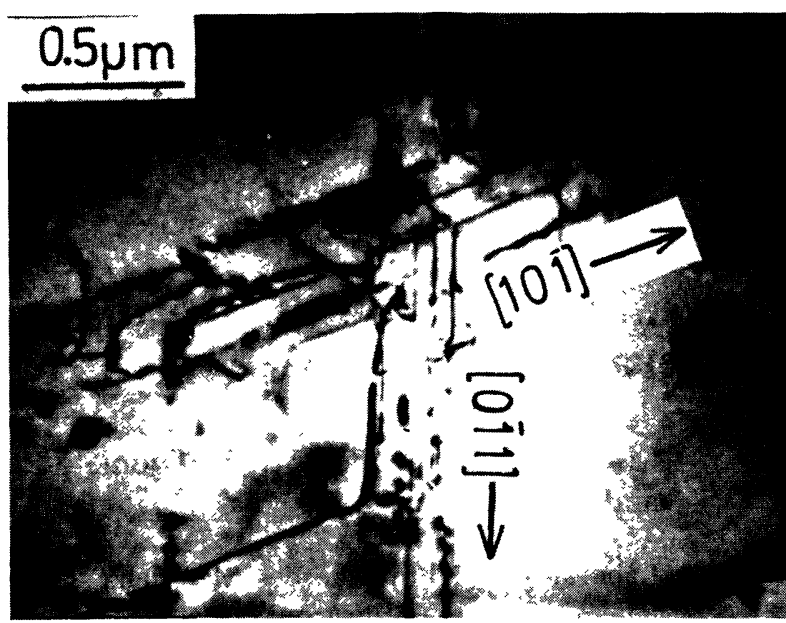

Fig. 1. - TEM micrograph on In doped GaAs deformed at $650{ }^{\circ} \mathrm{C}(923 \mathrm{~K})$ showing a typical array of dislocations with segments aligned with $\langle 110\rangle$ and $\langle 112\rangle . \sigma_{\text {final }} \simeq$ $35 \mathrm{MPa}$. Bright field image.

the activation of several glide planes with very little motion of dislocations out of their slip plane, in spite of the temperatul of deformation $\left(0.6 T_{\mathrm{M}}\right)$.

Many dislocations are pinned by points aligned with the $\langle 110\rangle$ directions (Fig. 2). The pinning points are probably superjogs formed by dislocation intersections. Narrow dipoles are formed (Fig. 2) with no loop formation, indicating that the diffusion

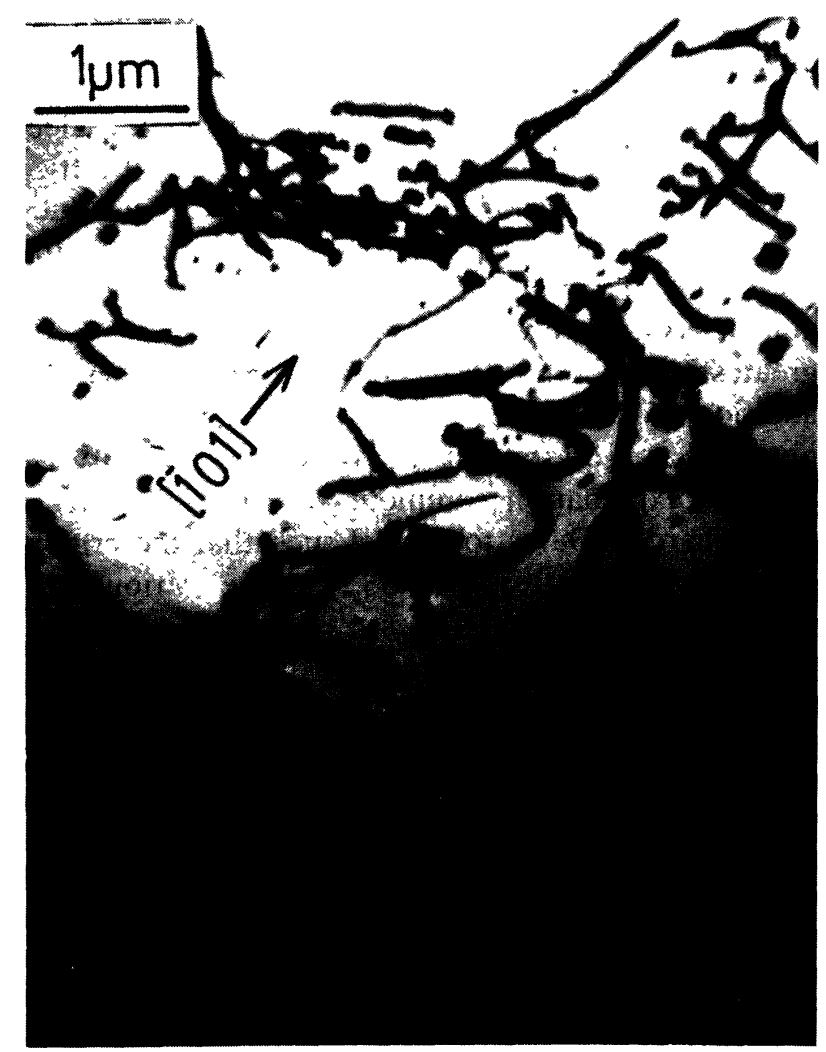

Fig. 2. - Typical area after deformation at $750^{\circ} \mathrm{C}$ $(1023 \mathrm{~K})$. Note the arrow dipoles with ends aligned along $\mathrm{a}\langle 110\rangle$ direction. $\sigma_{\text {final }} \simeq 58 \mathrm{MPa}$. 
along dislocations is not fast at that temperature $\left(0.7 T_{\mathrm{M}}\right)$. Large number of dipoles can be found (Fig. 3) with such separations that they were stable under the applied stress which, for equilibrium of dipoles, gives a distance $h$ between glide planes lower than about $100 \mathrm{~nm}$. At higher temperatures, dislocations can rearrange and form networks (Fig. 4) even for the small strain that we used. Crossslip and/or climb have become efficient at $0.85 T_{\mathrm{M}}$. For the example of figure 4 , the lattice is rotated around the [110] axis. Kikuchi lines allowed us to

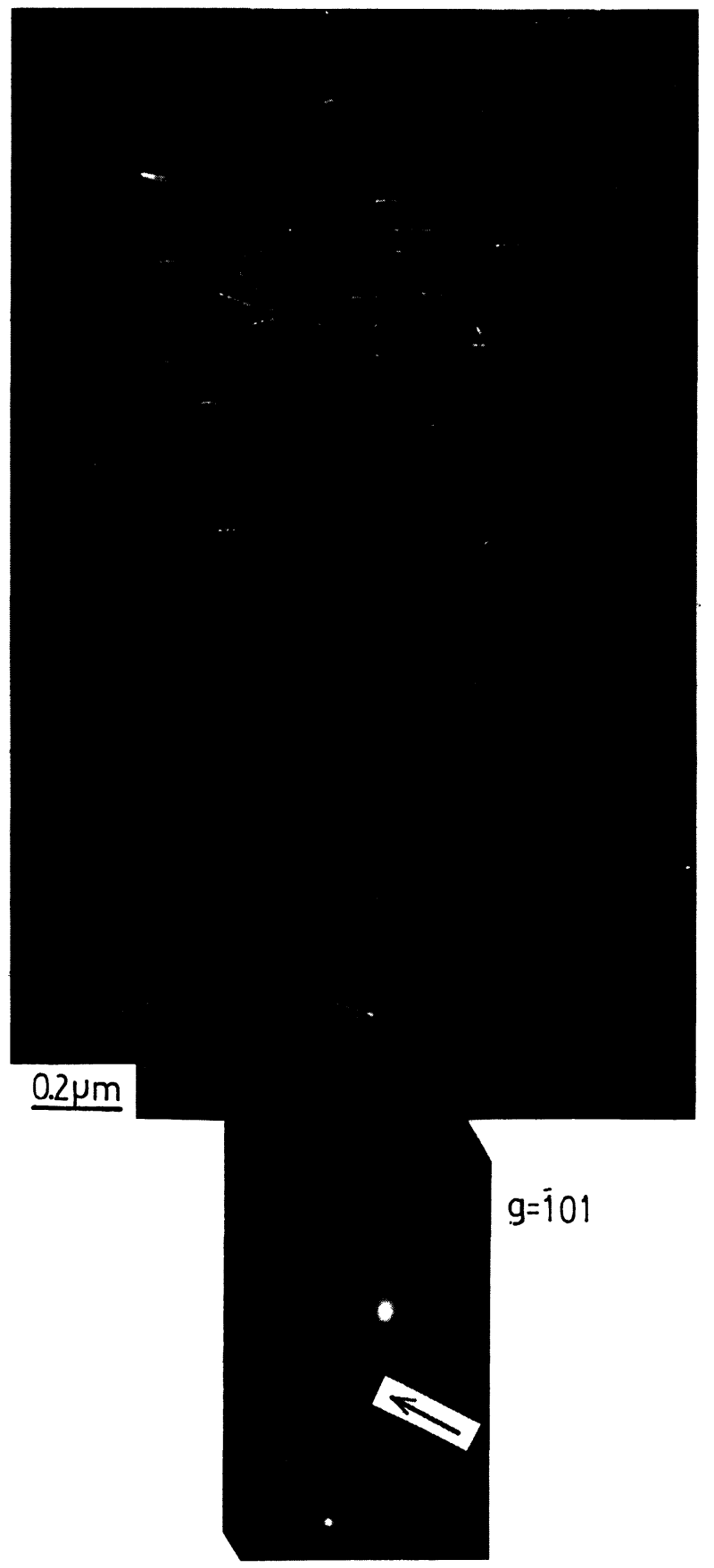

Fig. 3. - Weak beam dark field image showing dissociated $\alpha$ and $\beta$ dislocations and dipoles. Deformation at $750{ }^{\circ} \mathrm{C}$ $(1023 \mathrm{~K}) . \sigma_{\text {final }} \simeq 58 \mathrm{MPa}$.

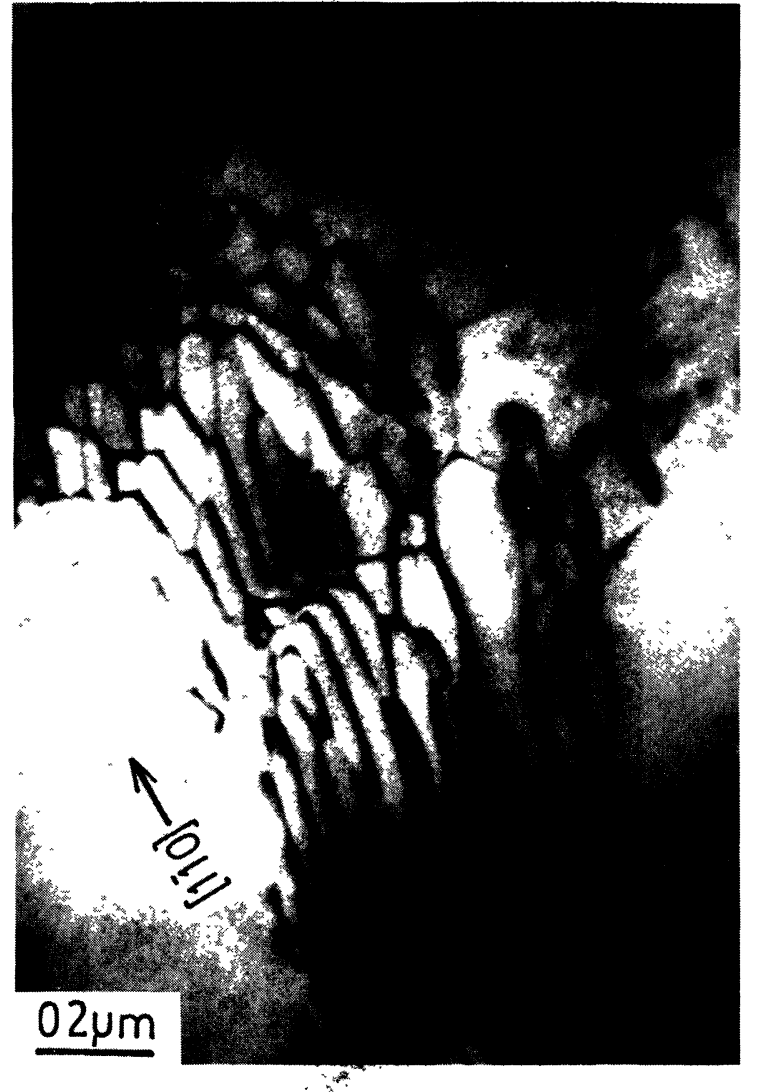

Fig. 4. - Sub-boundary observed in a specimen deformed at $1012{ }^{\circ} \mathrm{C}(1285 \mathrm{~K})$ made of $60^{\circ}$ dislocations. $\sigma_{\text {final }} \simeq$ $40 \mathrm{MPa}$.

calculate a misorientation of $5.5 \times 10^{-3} \mathrm{rad}$ across the sub-boundary, that agrees with the observed geometry of the dislocation network. These observations are similar to those made in other experiments on GaAs [7, 15] or in other materials. When looking at doped GaAs compared to undoped $\mathrm{GaAs}$, there is a trend towards elevated temperature for similar dislocation feature ; cross-slip and/or climb require higher thermal activation to become efficient.

3.2 Dissociation OF DISLOCATIONS. - We have examined isolated dislocations in samples deformed at various temperatures. The use of the $\mathbf{g} \cdot \mathbf{b}$ analysis allowed us to check that the Burgers vectors were of the $a / 2\langle 1 \overline{1} 0\rangle$ type. Dislocation lines were generally at $90^{\circ}$ (edge) or $60^{\circ}$ from the Burgers vector. Screws are mostly observed at low temperatures $[8,10]$.

As in our earlier work [11], we have used weak beam imaging to reveal the dissociation in two Shockley partials. We used the three $\langle 2 \overline{2} 0\rangle$ reflexions in the foil plane with a deviation $s \geqslant 0.01 \AA^{-1}$. The contrasts of partials have been discussed in a previous paper on the similar compound CdTe [20]. The figures 3 and 5 show dissociations of dislocations formed at $1023 \mathrm{~K}$ and $923 \mathrm{~K}$ respectively. The average distance between partials 

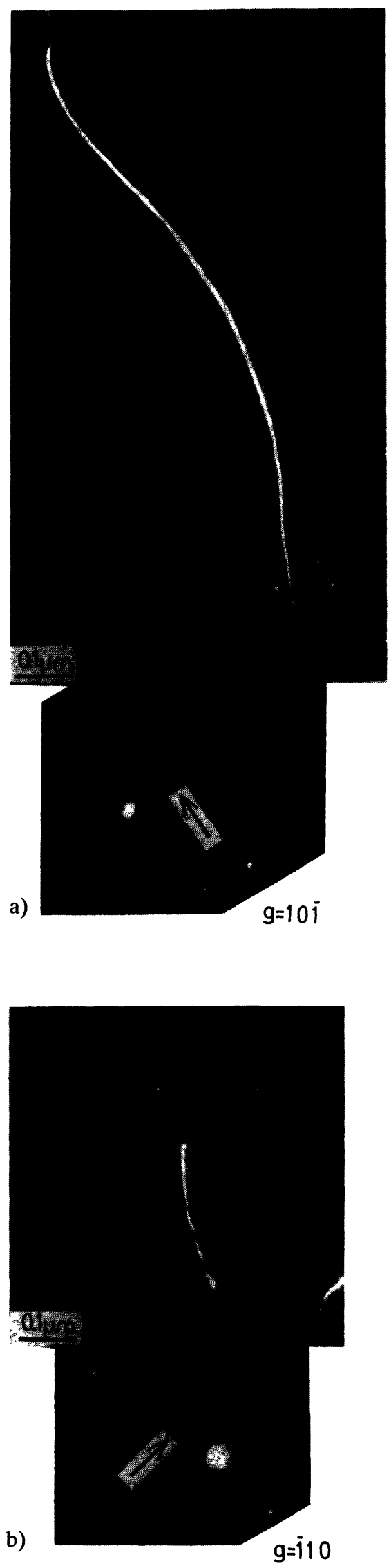

Fig. 5. - Deformation at $650^{\circ} \mathrm{C}(923 \mathrm{~K})$; weak beam dark field. $\sigma_{\text {final }} \approx 35 \mathrm{MPa}$. a) isolated dissociated dislocation ; b) fluctuation of partial separation. was independent of deformation temperatures. Values of $\Delta=12 \pm 1 \mathrm{~nm}$ for edges and $\Delta=9 \pm$ $1 \mathrm{~nm}$ for $60^{\circ}$ dislocations were found. These values correspond to a stacking fault energy of about $\gamma=27 \mathrm{~mJ} / \mathrm{m}^{2}$. $\gamma$ was evaluated in the isotropic elasticity approximation using as Poisson's ratio $\nu=0.27$ and shear modulus $\mu=4.5 \times 10^{10} \mathrm{~Pa}$ as elastic constants that we calculated ([21], p. 430) from anisotropic $C_{i j}$ tabulated in [22] ; such approximated formulae provide results very close to those calculated by a method taking into account anisotropy [16] for edge, $60^{\circ}$ and $30^{\circ}$ dislocations.

This value of $\gamma$ is substantially smaller than the one for undoped GaAs, where we found $49 \mathrm{~mJ} / \mathrm{m}^{2}$. The latter value agrees with most of those reported in the literature $[7,12,13,14,16,17]$.

Large partial separations have been observed in specific cases, such as after low temperature deformation under large stresses [8]. In this case, the force on partial dislocations resulting from the applied stress was larger than the interaction forces between partials. In our experiments, we are obviously far from such extreme mechanical state $[4,6]$. In our conditions, the applied external force on each partial is about one tenth of the mutual repulsive force between each component of the dissociated dislocation at equilibrium. The low stacking fault energy that we obtained in doped $\mathrm{GaAs}$ is, therefore, related to the presence of impurities.

This relation between doping and stacking fault energy was not observed in [11] where GaAs was less doped by about an order of magnitude and deformed at lower temperature. The decrease of stacking fault energy by doping $\mathrm{GaAs}$ was found up to $1273 \mathrm{~K}$; no clear influence of the temperature was found in spite of what is expected from free energy considerations. Fluctuations in the partial separation (Fig. 5b) can be ascribed to impurity concentration fluctuations. They cannot be ascribed to the pinning of partials in movement, on some randomly spread impurities; as noticed above $\left(\tau b^{\prime} \simeq 0.1 \gamma\right)$, this would modify the dissociation width of $10 \%$ only.

The highest the temperature, the most often we observed that projected image of dissociation is locally reduced. We believe this is due to dissociation by climb of the dislocations.

The decrease in stacking fault energy that we observed in GaAs containing indium may well be explained by the Suzuki segregation [21] or interaction between solute atoms and stacking fault. This effect always results in a decrease of the stacking fault energy [21]. The Suzuki effect can provide a mechanism to contribute to the dislocation locking revealed by static strain ageing [6], although it seemed to be dominated by elastic interactions. The influence of solutes on dissociation of dislocations is well known in f.c.c. metal alloys [19]. 
The densities of $\alpha$ and $\beta$ dislocations seem to be equivalent as revealed with the help of the contrast of dipoles (Fig. 3). This has also been reported for undoped GaAs [7, 11, 17] and for lightly doped GaAs [11]. The width of dissociation does not depend on the $\alpha$ or $\beta$ type (Fig. 3), as found also for undoped GaAs [16] and CdTe [20]. In indium doped $\mathrm{GaAs}$ it has been reported recently that $\alpha$ dislocations had an unusual dependence of mobility with stress [18] ; this cannot be ascribed to a specific behaviour of $\alpha$ dislocations with respect to dissociation.

\section{Conclusions and summary.}

It was observed that a large enough indium concentration in $\mathrm{GaAs}$ increases the dislocation partial separations after high temperature deformation. The observed increase is very likely smaller than the actual one at high temperature. This provides a mechanism for the reduction of grown-in dislocations in In doped GaAs crystals ; the increased dissociation makes cross-slip events and climb more unlikely rendering more difficult the homogenization of dislocation density during crystal growth. In our experimental conditions, the behaviours of $\alpha$ and $\beta$ dislocations are identical.

\section{Acknowledgments.}

One of the authors (M. J. M.) received a grant from the Ministerio de Educacion y Ciencia of Spain during the time of this work, which was also partly supported by the Action Intégrée $n^{\circ} 132-1987$.

\section{References}

[1] Djemel, A., Castaing, J., Heurtel, A., Svob, L. and Marfaing, Y., Philos. Mag. Lett. 55 (1987) 239.

[2] Duseaux, M., Thèse de Docteur Ingénieur, Paris VI (1982).

[3] Yamada, K., KohdaA, H., NaKanishi, H. and Hoshikawa, K., J. Crystal Growth 78 (1986) 36.

[4] Djemel, A. and Castaing, J., Europhys. Lett. 2 (1986) 611.

[5] Tabache, M. G., Bourret, E. D. and Elliot, A. G., Appl. Phys. Lett. 49 (1986) 289.

[6] Djemel, A., Castaing, J. and Duseaux, M., accepted to Philos. Mag. A (1987).

[7] Astie, P., Couderc, J. J., Chomel, P. and QuÉlard, D., Phys. Status Solidi A 96 (1986) 225.

[8] Kuesters, K. H., De Cooman, B. C. and Carter, C. B., Philos. Mag. A 3 (1986) 141.

[9] Lefebvre, A., ANDroussi, Y. and VANDerschaeve, G., Phys. Status Solidi A 99 (1987) 405.

[10] Boivin, P., Rabier, J., Garem, H. and Duseaux, M., Defects in Semiconductors, Ed. H. J. Von Bardeleben, Mater. Sci. Forum. 10-12 (1986) 781 .
[11] Jimenez-Melendo, M., DJemel, A., Rivière, J. P. and Castaing, J., Defects in Semiconductors, Ed. H. J. Von Bardeleben, Mater. Sci. Forum. 10-12 (1986) 791.

[12] Tanaka, M. and Jouffrey, B., Philos. Mag. A 50 (1984) 733.

[13] Maksimov, S. K., Ziegler, M., Khodos, I. I., SNIGHIRYOVA, I. I. and SHIKHSAIDOV, M. Sh., Phys. Status Solidi A 84 (1984) 79.

[14] Ponce, F. A., Anderson, G. B., HaAsen, P. and Brion, H. G., Defects in Semiconductors, Ed. H. J. Von Bardeleben, Mater. Sci. Forum. 10-12 (1986) 775.

[15] Laister, D. and Jenkins, G. M., J. Mater. Sci. 8 (1973) 1218.

[16] Gomez, A. M. and Hirsch, P. B., Philos. Mag. A 38 (1978) 733.

[17] Feuillet, G., Diss. Master of Science, Oxford, 1982.

[18] Yonenaga, I., Sumino, K. and Yamada, K., Appl. Phys. Lett. 48 (1986) 326.

[19] Gallagher, P. C. J., Metall. Trans. 1 (1970) 2429.

[20] Orlova, A., Rivière, J. P. and CASTAing, J., Revue Phys. Appl. 20 (1985) 449.

[21] HiRTh, J. P. and LOTHE, J., Theory of dislocations (John Wiley and Sons) 2nd Edition, 1982.

[22] Huntington, H. B., Solid State Phys. 7 (1958) 213. 